\title{
Diagnostic investigation of ventilator-associated pneumonia using bronchoalveolar lavage: comparative study with a postmortem lung biopsy
}

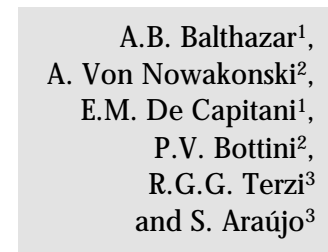

\section{Correspondence}

A.B. Balthazar

Departamento de Clínica Médica

FCM, UNICAMP

Caixa Postal 6166

13083-970 Campinas, SP

Brasil

Fax: + 55-19-287-6436

E-mail: alipio@ unicamp.br

Publication supported by FAPESP.

.....................

Received August 16, 2000 Accepted May 29, 2001

\author{
'Disciplina de Pneumologia, Departamento de Clínica M édica, \\ Faculdade de Ciências M édicas, Hospital de Clínicas, \\ Universidade Estadual de Campinas, Campinas, SP, Brasil \\ ${ }^{2}$ Departamento de Patologia Clínica, Faculdade de Ciências M édicas, \\ Hospital de Clínicas, Universidade Estadual de Campinas, Campinas, SP, Brasil \\ ${ }^{3}$ Disciplina de Fisiologia e M etabologia Cirúrgica, D epartamento de Cirurgia, \\ Unidade de Terapia Intensiva, Faculdade de Ciências M édicas, \\ Hospital de Clínicas, Universidade Estadual de Campinas, Campinas, SP, Brasil
}

\section{Abstract}

The purpose of the present study was to validate the quantitative culture and cellularity of bronchoalveolar lavage (BAL) for the diagnosis of ventilator-associated pneumonia (VAP). A prospective validation test trial was carried out between 1992 and 1997 in a general adult intensive care unit of a teaching hospital. Thirty-seven patients on mechanical ventilation with suspected VAP who died at most three days after a BAL diagnostic procedure were submitted to a postmortem lung biopsy. BAL effluent was submitted to Gram staining, quantitative culture and cellularity count. Postmortem lung tissue quantitative culture and histopathological findings were considered to be the gold standard exams for VAP diagnosis. According to these criteria, 20 patients (54\%) were diagnosed as having VAP and 17 $(46 \%)$ as not having the condition. Quantitative culture of BAL effluent showed $90 \%$ sensitivity $(18 / 20), 94.1 \%$ specificity $(16 / 17)$, $94.7 \%$ positive predictive value and $88.8 \%$ negative predictive value. Fever and leukocytosis were useless for VAP diagnosis. Gram staining of BAL effluent was negative in $94.1 \%$ of the patients without VAP (16/17). Regarding the total cellularity of BAL, a cut-off point of 400,000 cells/ml showed a specificity of $94.1 \%$ (16/17), and a cut-off point of $50 \%$ of BAL neutrophils showed a sensitivity of $90 \%(19 / 20)$. In conclusion, BAL quantitative culture, Gram staining and cellularity might be useful in the diagnostic investigation of VAP.
Key words

- Nosocomial pneumonia

- Mechanical ventilation

- Diagnostic techniques

- Bronchoalveolar lavage

- Lung biopsy

- Ventilator-associated pneumonia 


\section{Introduction}

Nosocomial pneumonia is defined as the development of pneumonia at least $48 \mathrm{~h}$ after hospitalization and not incubating at the time of admission. Nowadays, it is the most common nosocomial infection, and the first one in morbidity and mortality (1-3). Although patients submitted to mechanical ventilation (MV) do not represent the majority of patients with nosocomial pneumonia, they are those at higher risk of acquiring it (3). Ventilator-associated pneumonia (VAP) is defined as pneumonia occurring in a patient on $\mathrm{MV}$ at least for $48 \mathrm{~h}(4,5)$. The mortality rate associated with VAP can vary from 33 to $71 \%$, depending on the virulence of the microorganisms and the severity of the clinical condition (5). However, it is hard to know which is the contribution of VAP to global mortality of infected patients since they already suffer from threatening diseases $(1,6,7)$.

VAP is often caused by Gram-negative bacilli, resulting from the aspiration of oropharyngeal cavity-contaminated secretions (8). Colonization of the oropharynx by Gram-negative bacilli is usually associated with chronic diseases, recent use of antibiotics and endotracheal intubation $(8,9)$. The relationship between continuous aspiration of colonized material around the endotracheal cuff and the development of pneumonia has been well established $(2,8)$. At some hospitals, Staphylococcus aureus is the most frequently isolated microorganism, especially the methicillin-resistant strain (10).

The correct diagnosis of VAP remains a challenge due to the low accuracy of current clinical criteria, such as the presence of fever, leukocytosis, purulent tracheal secretions or pulmonary radiographic opacities $(1,11)$. Many patients on MV have severe background diseases, increased oropharyngeal colonization, and several reasons to present fever and leukocytosis $(1,9,12)$. Purulent sputum might follow endotracheal intubation and leakage of secretions around the endotracheal tube. Radiographic pulmonary opacities can be secondary to pulmonary edema, pulmonary thromboembolism, atelectasis and acute respiratory distress syndrome (ARDS), among others. Thus, a high rate of uncertainty turns the current clinical criteria inadequate for the correct diagnosis of VAP (13). Therefore, the main objective of the present study was to validate the quantitative culture and cellularity of bronchoalveolar lavage (BAL) in the diagnosis of VAP by comparing them to the gold standard exam, i.e., quantitative culture of a postmortem lung tissue biopsy plus histopathological findings compatible with pneumonia.

\section{Patients and Methods}

\section{Patient selection}

The present study was carried out between 1992 and 1997 at the General Adult Intensive Care Unit of the University Hospital, Campinas State University, Campinas, SP, Brazil. During this period, 123 patients with suspected VAP were submitted to diagnostic BAL as a routine procedure. Among them, 37 patients were selected following a pre-established inclusion criterion, i.e., patients on MV for more than three days presenting thoracic radiographic shadows suggestive of pneumonia associated with purulent tracheal secretion. All selected patients were submitted to fiberoptic bronchoscopy and BAL. Patients included in the study had died at least three days after bronchoscopy, when a piece of lung tissue was removed for histopathological and microbiological examination. Although initially selected, we further excluded from the study all patients whose antibiotic regimens had been changed between the BAL procedure and the time of death, patients with acquired immunodeficiency syndrome, and patients with isolated germs different from bacteria. None of the included patients were under routine prophylactic therapy for gastrointestinal or res- 
piratory tract decontamination.

The main reason for MV, use of antibiotics at the time of the BAL procedure and at the time of death, blood leukocyte counts, presence of fever and type of thoracic radiographic findings were analyzed as predictor variables. Histopathological findings compatible with pneumonia and positive lung tissue microbiological culture coincident with BAL culture were considered as the outcome variables.

The study protocol was approved by the local Ethics Committee and informed consent for a postmortem lung biopsy was obtained from the patients' relatives or guardians.

\section{Methods}

Bronchoalveolar lavage. BAL was performed by fiberoptic bronchoscopy after sedation with midazolam plus fentanyl or sodium thiopental. In some cases, a short action neuromuscular blocking agent was also used. No local anesthetics were routinely used. During the procedure, ventilatory parameters were adjusted to $\mathrm{FiO}_{2}=1.0$, inspiratory peak flow of $601 / \mathrm{min}$ or less, and peak pressure alarm at a level that allowed adequate ventilation, i.e., tidal volume as close as possible to that prior to the procedure, and all patients were kept under rigorous cardiopulmonary monitoring (systemic arterial pressure, heart rate and rhythm, and pulse oximetry). Fiberoptic bronchoscopy and BAL technique were performed as recommended by Meduri and Chastre (14). Twenty-milliliter saline aliquots were injected each time, for a total of $200 \mathrm{ml}(10$ aliquots). The lung segment was chosen based on simple chest radiographic images, thoracic computed tomography scan when available, and by visualization of purulent secretion from a specific segmental bronchus during bronchoscopy. The first $40 \mathrm{ml}$ of fluid obtained during the procedure was named bronchial aliquot, and the last $160 \mathrm{ml}$ was named alveolar aliquot. An Olympus BF type 20D apparatus was used. Cleaning and disinfecting were done using mechanical methods, initially brushing the internal and external parts of the equipment and washing it with saline. The equipment was then immersed in a soap solution (Endozime AW plus ${ }^{\circledR}$ ), rinsed with clean water, immersed again in a $2 \%$ glutaraldehyde solution $\left(\right.$ Glutaron $^{\mathbb{R}}$ ) for $30 \mathrm{~min}$, and finally rinsed with sterile water.

$B A L$ processing. The bronchial aliquot was processed for a direct search of fungi (Grocott staining) and mycobacteria (ZiehlNeelsen staining). Five milliliters of the 40$\mathrm{ml}$ alveolar aliquot was selected for microbiological examination, including quantitative culture, Gram staining, and culture for mycobacteria and fungi. Gram and acid-fast staining, as well as a direct search for fungi, were performed after cytocentrifugation. Quantitative culture was performed as recommended by Baselski et al. (4) and was considered positive when bacterial growth was $10^{4}$ colony-forming units per $\mathrm{ml}\left(10^{4}\right.$ $\mathrm{cfu} / \mathrm{ml}$ ) or more. The remaining part of the alveolar aliquot was homogenized and vortexed for 30 to $60 \mathrm{~s}$ and submitted to specific cell counting using a Neubauer chamber, and the results were expressed as number of cells per ml (4). Differential counts were made after cytocentrifugation ( $10 \mathrm{~min}$ at 800 $\mathrm{rpm}$ ), and staining by basic blue of MayGrünwald following room temperature drying, using a sample of 50 to $500 \mu$ inversely proportional to the number of cells present in the sample. For differential counts, 300 to 500 cells were counted under a simple light microscope at 100 times magnification, and the results were expressed as percentages of lymphocytes, monocytes, neutrophils, macrophages, epithelial cells, etc. Epithelial cells were used as markers of contamination, and when they were present at rates of $2 \%$ or more, the BAL sample was excluded from the study.

Postmortem lung biopsy. Lung tissue fragments were obtained at least one hour after death through an intercostal incision extend- 
ing from the median clavicular line to the median axillary line. The segments chosen for biopsy were from regions where BAL was performed. Two fragments were taken, one measuring approximately $1 \times 1 \times 1 \mathrm{~cm}$ and the other $7 \times 4 \times 4 \mathrm{~cm}$. The smaller fragment was placed in $0.9 \%$ saline and sent to the microbiology laboratory for quantitative culture and the larger one was placed in $10 \%$ formalin and sent to the anatomic pathology laboratory.

Lung biopsy fragment processing. The dilution technique was used for lung tissue culture and results exceeding $10^{4} \mathrm{cfu} / \mathrm{ml}$ were considered positive. The interpretation of the histopathological results was based on the criteria described by Katzenstein and Askin (15). Definite diagnosis of pneumonia was established only when histopathological findings were in accordance with the quantitative culture results. Otherwise, the case was excluded from analysis.

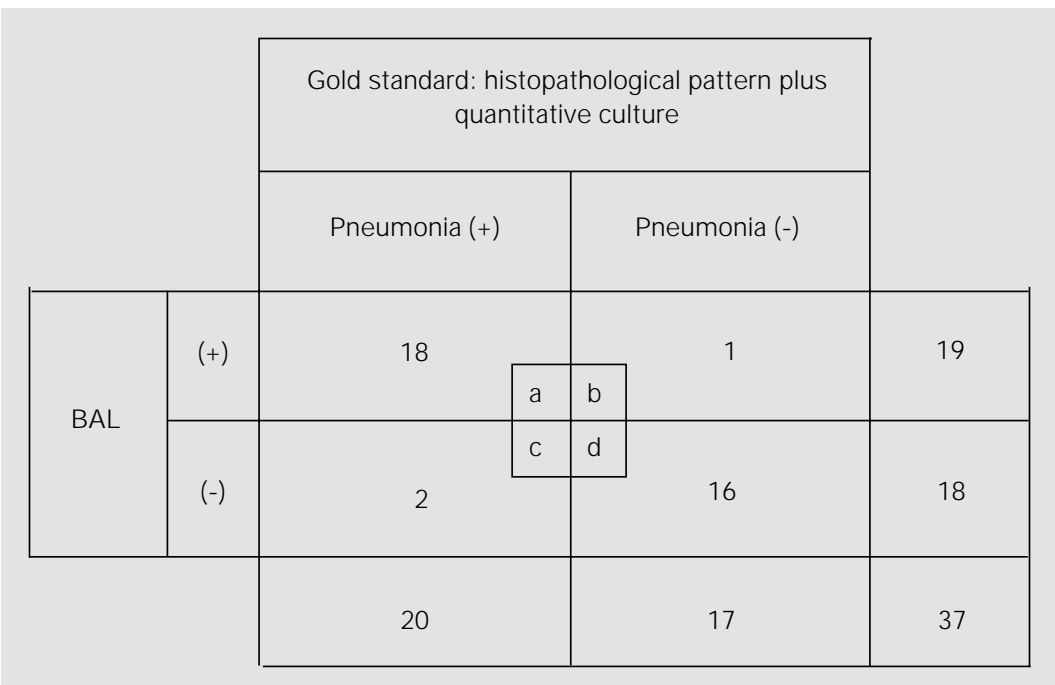

Sensitivity $=a / a+c=18 / 20=90 \%$

Specificity $=d / b+d=16 / 17=94.1 \%$

Positive predictive value $=a / a+b=18 / 19=94.7 \%$

Negative predictive value $=d / c+d=16 / 18=88.8 \%$

Prevalence of pneumonia $=20 / 37=54 \%$

Accuracy $=a+d / a+b+c+d=24 / 37=64.8 \%$

Figure 1. Summary of data concerning validation of bronchoalveolar lavage (BAL) results as a diagnostic test for pneumonia. The gold standard parameters were open lung biopsy histopathological pattern for pneumonia plus quantitative culture of lung tissue.

\section{Data analysis}

To validate the diagnostic tests, we used as gold standard for a definite diagnosis of pneumonia a compatible pattern obtained by histological examination plus a positive quantitative culture of lung tissue as described above. Sensitivity, specificity, positive and negative predictive values, prevalence of pneumonia in the sample and accuracy of the test were calculated by the method of Sackett et al. (16), using a cut-off value that maximized the true-positive rate, in the case of continuous variables. Cell counts are presented as a box plot graph using Minitab 10.1 software.

\section{Results}

We studied 37 patients, 26 males (70.3\%) and 11 females (29.7\%) aged on average 37.5 years. Acute respiratory failure was due to clinical causes in 17 patients and to surgical pathologies in 11 and was secondary to trauma in 9. The radiographic thoracic findings showed localized heterogeneous opacities in 6 patients, localized homogenous opacities in 10 and diffuse heterogeneous opacities in 21. All patients were taking antibiotics at the time of BAL.

A definite diagnosis of pneumonia was made in 20 patients (54\%). Patients without a histopathological diagnosis of pneumonia (17/37, 45.9\%) presented the following isolated or associated pathological findings: ARDS (nine cases), interstitial fibrosis (three cases), diffuse alveolar damage (three cases), diffuse alveolar edema (two cases), pulmonary embolism (three cases), and pulmonary embolism of neoplastic origin (one case).

Considering quantitative culture of lung tissue biopsy and histopathological diagnosis of pneumonia as the diagnostic gold standard, we found that quantitative culture of BAL showed $90 \%$ sensitivity $(18 / 20)$ and $94.1 \%$ specificity (16/17), with $94.7 \%$ positive predictive value, and $88.8 \%$ negative 
predictive value, with pneumonia prevalence expected to be $54 \%$ (Figure 1).

Table 1 shows the types of bacteria isolated from BAL and from the lung biopsy.

Table 2 shows the index of agreement between Gram stain and the results of BAL quantitative culture, mean cell counts in BAL (total cells, alveolar macrophages and neutrophils), and sensitivity and specificity of these findings according to pre-established cut-off values.

Figure 2 shows the distribution of BAL cellularity in a box plot graph and the parameters for test validity analysis using a cut-off value of 400,000 cells $/ \mathrm{ml}$.

Sensitivity and specificity were 50 and $76.4 \%$ for fever $\left(>38^{\circ} \mathrm{C}\right)$ and 60 and $76.4 \%$ for leukocytosis ( $>10,000$ total leukocytes), respectively. The complementary association of these two parameters was not additive. The results obtained for Gram staining, total cellularity, macrophages and neutrophil differentiation counts in BAL for the analysis of test validity are presented in Table 2.

BAL procedure complications were observed in seven cases (18.8\%): hemorrhage in four, hypoxemia in two and association of hemorrhage and hypoxemia in one case. All complications were of mild intensity, none of them resulting in the interruption of the procedure.

\section{Discussion}

VAP continues to be a diagnostic challenge. Only a few studies on humans using postmortem lung biopsy to assess the frequency of VAP have been published (1725).

The wide variation in VAP prevalence in these different studies is due to the size of the specimens examined, the use or not of antibiotics prior to lung biopsy, as well as to the type of antimicrobial regimen used. In any case, the gold standard for VAP diagnosis is still a matter of debate in the specialized literature. Rouby et al. (18) have considered that histological examination of every pulmonary segment could give a most realistic view of the prevalence of VAP. In their study, they performed unilateral pneumonectomy for histological assessment. Marquette et al. (20) found a $67 \%$ frequency of VAP when performing bilateral pneumonectomy for histological examination, which must explain their high prevalence index. Using small lung fragments of $1 \times 1 \times 1 \mathrm{~cm}$, Chastre et al. (17) found only a $23 \%$ rate of histologically defined VAP, probably due to the tiny specimen examined. However, other studies also using tiny lung fragments found higher frequencies of VAP, such as 55\% (21), 60\% (19), and 54\% (present study). Whether our own prevalence was underestimated due to the size of the fragment examined is a matter of speculation, considering the $67 \%$ index found by Marquette et al. (20) using bilateral pneumonectomy. In this respect, further studies are needed to provide new information later on.

Regarding a diagnosis of a disease other

Table 1. Microorganisms isolated from bronchoalveolar lavage and a lung biopsy in 20 cases of ventilator-associated pneumonia.

Patients Bacteria found and type of examination used

1 Acinetobacter baumanii (BAL $+\mathrm{LB})$

2 Staphylococcus aureus (BAL $+\mathrm{LB})$

3 Pseudomonas mirabilis (BAL + LB)

4 A. baumanii (BAL + LB) and P. aeruginosa (LB)

5 S. pneumoniae (BAL + LB)

6 S. aureus (BAL + LB)

7 P. aeruginosa + A. baumanii (BAL + LB)

8 Enterobacter cloacae + A. baumanii $(B A L+L B)$

9 S. aureus (LB)

10 S. aureus (BAL + LB)

11 S. aureus (BAL + LB) and E. cloacae (LB)

12 P. aeruginosa (BAL + LB)

13 Hemophilus influenzae $+\mathrm{S}$. aureus $+\mathrm{S}$. pyogenes $+\mathrm{S}$. viridans $(\mathrm{BAL}+\mathrm{LB})$

14 P. aeruginosa (BAL + LB)

15 S. aureus (BAL + LB)

16 S. aureus (BAL + LB)

17 Serratia liquefaciens (BAL + LB)

18 A. baumanii (BAL + LB)

19 A. baumanii (BAL + LB)

20 P. aeruginosa (LB)

BAL: bronchoalveolar lavage; LB: lung biopsy. 
than VAP, the most common respiratory histopathological finding in our patients was ARDS, followed by diffuse alveolar damage and pulmonary fibrosis. Torres et al. (19) found a $43 \%$ rate of alveolar hemorrhage and a $29 \%$ rate of diffuse alveolar damage in their patients. Marquette et al. (20) found that the most common diagnosis was diffuse alveolar damage, followed by pulmonary fibrosis. In a study on 83 patients, Rouby et al. (18) detected 28 with diffuse alveolar damage and 13 with pulmonary fibrosis.

Only a few studies have assessed the sensitivity and specificity of BAL examination using a postmortem lung biopsy as the gold standard for the diagnosis of VAP.

A possible reason for the high discrepancy in the reported frequency of VAP could be the wide variation in test validation for the use of BAL in its diagnosis. The use of broad spectrum antibiotics prior to the bi- opsy procedure is probably one of the most important reasons for this variation.

In our study, BAL permitted the isolation of 25 of 27 bacterial species found in the culture of the lung fragment in patients with VAP, accounting for $92.5 \%$ of them. Five of 20 VAP patients $(25 \%)$ had polymicrobial pneumonia. Association of germs in lung biopsy culture occurred only in four patients (see Table 1). Most published studies have pointed out the polymicrobial status of nosocomial pneumonia $(26,27)$. Bartlett et al. (26) found polymicrobial pneumonia in 54\% of 159 cases. Similarly, Fagon et al. (1) found a $40 \%$ rate in 52 cases, and Torres et al. (27) found a $13 \%$ rate in 78 cases.

The germ most frequently isolated from our VAP patients was Staphylococcus aureus (from lung fragments in eight cases and from BAL in eight cases), followed by Acinetobacter baumanii (five in biopsy examination

Table 2. Validation test for the other bronchoalveolar lavage variables. The gold standard parameters were open lung biopsy histopathological pattern for pneumonia plus quantitative culture of a lung tissue biopsy.

\begin{tabular}{|c|c|c|c|c|}
\hline Diagnostic test & $\begin{array}{l}\text { Results (+) or (-): means } \\
\text { and cut-off values }\end{array}$ & $\operatorname{VAP}(+): \mathrm{N}=20$ & $\operatorname{VAP}(-): \mathrm{N}=17$ & $\begin{array}{l}\text { Validation test } \\
\text { parameters }\end{array}$ \\
\hline Gram stain & $\begin{array}{l}(+) \\
(-)\end{array}$ & $\begin{array}{c}17 \\
3\end{array}$ & $\begin{array}{r}1 \\
16\end{array}$ & $\begin{array}{l}\text { Sensitivity }=85 \% \\
\text { Specificity }=94.1 \% \\
\text { PPV }=94.4 \% \\
\text { NPV }=84.2 \% \\
\text { Accuracy }=89.1 \%\end{array}$ \\
\hline Total cellularity & $\begin{array}{c}\text { Means } \\
>400,000 \\
<400,000\end{array}$ & $\begin{array}{c}804,975 \\
18 \\
2\end{array}$ & $\begin{array}{c}232,352 \\
1 \\
16\end{array}$ & $\begin{array}{l}\text { Sensitivity }=90 \% \\
\text { Specificity }=94.1 \% \\
\text { PPV }=94.7 \% \\
\text { NPV }=88.8 \% \\
\text { Accuracy }=64.8 \%\end{array}$ \\
\hline Alveolar macrophages & $\begin{array}{l}\text { Means } \\
<30 \% \\
>30 \%\end{array}$ & $\begin{array}{c}14.1 \% \\
18 \\
2\end{array}$ & $\begin{array}{c}55.7 \% \\
4 \\
13\end{array}$ & $\begin{array}{l}\text { Sensitivity }=90 \% \\
\text { Specificity }=76.4 \% \\
\text { PPV }=81.8 \% \\
\text { NPV }=86.6 \% \\
\text { Accuracy }=83.7 \%\end{array}$ \\
\hline Neutrophils & $\begin{array}{l}\text { Means } \\
>50 \% \\
<50 \%\end{array}$ & $\begin{array}{c}77.8 \% \\
19 \\
1\end{array}$ & $\begin{array}{c}28.7 \% \\
1 \\
16\end{array}$ & $\begin{array}{l}\text { Sensitivity }=95 \% \\
\text { Specificity }=94.1 \% \\
\text { PPV }=95 \% \\
\text { NPV }=94.1 \% \\
\text { Accuracy }=100 \%\end{array}$ \\
\hline
\end{tabular}

(+): positive; (-): negative; PPV: positive predictive value; NPV: negative predictive value; VAP: ventilatorassociated pneumonia. 
and five in BAL), and Pseudomonas aeruginosa (five in biopsy specimens and four in BAL). These results agree with many published studies, where the most frequently isolated microorganisms were Gram-negative bacilli $(1,17,26-32)$ and Staphylococcus aureus (mainly the methicillin-resistant strain) (1,33-37). When compared with other studies that used postmortem lung biopsy examination, our culture results also showed Gram-negative bacilli and Staphylococcus aureus as the most important causal agents, as also reported by Torres et al. (19), Papazian et al. (22), and Marquette et al. (20).

The Gram staining results presented in Table 1 reveal that patients without VAP showed a good correlation between culture results and negative direct Gram staining examination $(16 / 17$ patients $=94.1 \%)$. This is a very high specificity index, excluding in daily clinical practice a diagnosis of pneumonia in most of the suspected cases when Gram staining is negative. Marquette et al. (20) found a specificity of $87.5 \%$ (negative Gram staining in seven of eight cases with negative tissue cultures), and Papazian et al. (22) found $100 \%$ specificity in their study. However, the sensitivity of Gram staining in our study was only $85 \%(17 / 20)$. When considering the microorganism species, when each Gram stain is matched to each tissue culture result, coincidence occurs in only $55 \%(11 / 20)$. Low levels of sensitivity were also reported in the studies of Marquette et al. (20) (47.3\%), and Papazian et al. (25) $(56 \%)$.

In our study, despite the wide variation in total BAL cellularity (a mean of 804,975 cells/ml, ranging from 140,000 to $1,745,000$ in VAP patients; a mean of 232,352 cells $/ \mathrm{ml}$, ranging from 52,500 to $1,050,000$ in patients without VAP) (Figure 2), using a cut-off point of 400,000 cells $/ \mathrm{ml}$ we can define a sensitivity of $90 \%(18 / 20)$ and a specificity of $94.1 \%(16 / 17)$. In the study of Marquette et al. (20), despite the fact that the average number of BAL cells was higher in patients with pneumonia, there was no significant difference between groups. Papazian et al. (25) obtained the same results, showing that this parameter must be interpreted with caution in clinical practice.

Relative neutrophil number in BAL was also higher in patients with pneumonia $(95 \%$ of the cases had $50 \%$ or more neutrophils). The same results were obtained by Marquette et al. (20). Despite significant differences between groups in their study, they concluded that this parameter has a poor predictive value when the variation and range of values are too wide. Papazian et al. (25) found no differences in neutrophil numbers between groups. However, Kirtland et al. (23) found that $50 \%$ of neutrophils in BAL is a good cut-off value to exclude pneumonia (100\% specificity). Their patients with pneumonia showed a mean percentage of BAL neutrophils of $75 \%(50-96 \%)$ versus $46 \%$ (1-96\%) in the group without pneumonia (23). In this respect, our results, associated with those of Kirtland et al. (23), should stimulate further studies on the role of BAL neutrophils in the diagnosis of VAP.

Since a large number of critically ill patients cannot wait for the result of culture to initiate antibiotic therapy, the clinical and radiographic suspicion of VAP allied to BAL

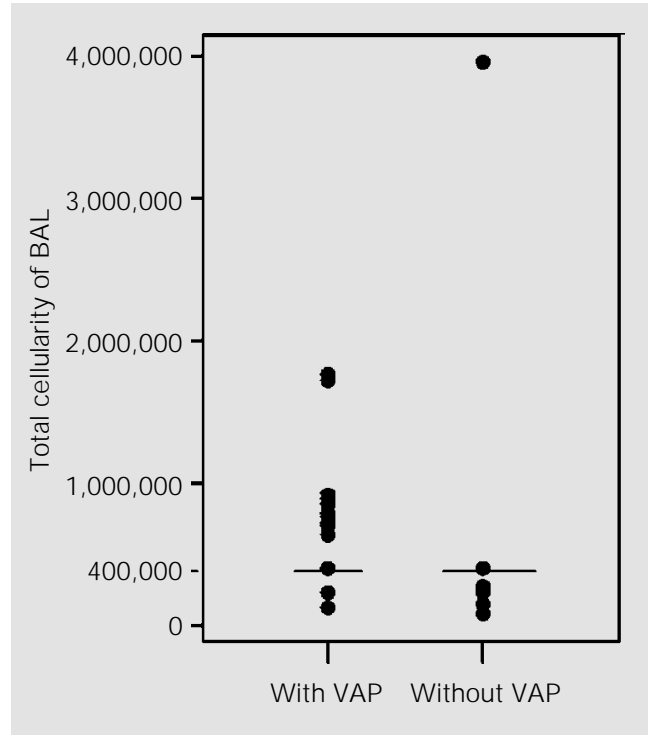

Figure 2. Total number of cells in bronchoalveolar lavage (BAL) from the two groups of patients studied showing the cut-off value for diagnostic validity. VAP, ventilator-associated pneumonia. 
findings, such as total cellularity and percentage of neutrophils, should contribute to the diagnosis and institution of early therapy. It seems reasonable that additional studies should be carried out on the cellularity of BAL, since the early use of antibiotics in this kind of patients will inevitably compromise the results of BAL or lung tissue culture.

The number of BAL procedure complications observed in our study was rather high $(18.9 \%)$, but all of them were self- limited, not interfering with the continuity of the procedure in any case.

In conclusion, our data indicate that BAL quantitative culture, Gram staining and cellularity might be useful tools in the diagnostic investigation of VAP. It is evident that further studies are needed to assess the role of better diagnostic procedures (invasive or not) in VAP, regarding endpoints such as related morbidity, overall mortality, and health care costs.

\section{References}

1. Fagon J Y, Chastre J, Domart $Y$, Trouillet J L, Pierre J , Darne C \& Gibert C (1989). Nosocomial pneumonia in patients receiving continuous mechanical ventilation: prospective analysis of 52 episodes with use of a protected specimen brush and quantitative culture techniques. American Review of Respiratory Disease, 139: 877884.

2. Craven $D E$, Steger $K A \&$ Barber TW (1991). Preventing nosocomial pneumonia: state of the art and perspectives for the 1990s. American J ournal of Medicine, 91 (Suppl 3B): 44S-53S.

3. Tablan OC, Anderson LJ, Arden $\mathrm{NH}$, Breiman RF, Butler JC, McNeil MM \& Pearson ML (1997). Guidelines for prevention of nosocomial pneumonia. Part I: an overview of the prevention of nosocomial pneumonia, 1994. Morbidity and Mortality Weekly Report, 46: 1-43.

4. Baselski VS, El-Torky M, Coalson JJ \& Griffin J P (1992). The standardization of criteria for processing and interpreting laboratory specimens in patients with suspected ventilator-associated pneumonia. Chest, 102 (Suppl): 571S-579S.

5. Sterling TR, Ho EJ , Brehm WT \& Kirkpatrick MB (1996). Diagnosis and treatment of ventilator-associated pneumonia - impact on survival. A decision analysis. Chest, 110: 1025-1034.

6. Fagon J Y, Chastre J, Hance AJ , M ontraers PH, Novara A \& Gibert C (1993). Nosocomial pneumonia in ventilated patients: a cohort study evaluating attributable mortality and hospital stay. American J ournal of Medicine, 94: 281-288.

7. Rello J , Ausina V, Ricart M, Castella J \& Prats G (1993). Impact of previous antimicrobial therapy on the etiology and outcome of ventilator-associated pneumonia.
Chest, 104: 1230-1235.

8. Valles J, Artigas A, Rello J, Bonson SN, Fontanal SD, Blanch L, Fernandez R, Baigorri F \& Mestre J (1995). Continuous aspiration of subglottic secretions in preventing ventilator-associated pneumonia. Annals of Internal Medicine, 122: 179186.

9. J ohanson J r WG, Pierce AK, Sanford J P \& Thomas GD (1972). Nosocomial respiratory infection with Gram-negative bacilli: the significance of colonization of the respiratory tract. Annals of Internal Medicine, 77: 701-706.

10. Faling LJ (1988). New advances in diagnosing nosocomial pneumonia in intubated patients. American Review of Respiratory Disease, 137: 253-255.

11. Fagon J Y, Chastre J, Hance AJ, Guiguet M, Trouillet J L, Domart Y, Pierre J \& Gibert C (1988). Detection of nosocomial lung infection in ventilated patients. Use of a protected specimen brush and quantitative culture techniques in 147 patients. American Review of Respiratory Disease, 138: 110-116.

12. Atherton ST \& White DJ (1978). Stomach as source of bacteria colonizing respiratory tract during artificial ventilation. Lancet, 2: 968-969.

13. Kirkpatrick MB \& Bass J rJ B (1989). Quantitative bacterial cultures of bronchoalveolar lavage fluids and protected brush catheter specimens from normal subjects. American Review of Respiratory Disease, 139: 546-548.

14. Meduri GU \& Chastre J (1992). The standardization of bronchoscopic techniques for ventilator-associated pneumonia. Chest, 102 (Suppl 1): 557S-564S.

15. Katzenstein AA \& Askin FB (1990). Surgical Pathology of Non-Neoplastic Lung Dis- ease. 2nd edn. W.B. Saunders, Philadelphia.

16. Sackett DL, Haynes RB \& Tugwell $P$ (1985). Clinical Epidemiology. A Basic Science for Clinical Medicine. Little, Brown $\&$ Company, Boston/Toronto.

17. Chastre J, Viau F, Brun P, Pierre J, Dauge MC, Bouchama A, Akesbi A \& Gibert C (1984). Prospective evaluation of the protected specimen brush for the diagnosis of pulmonary infections in ventilated patients. American Review of Respiratory Disease, 130: 924-929.

18. Rouby J J, Martin de Lassale E, Poete $P$, Nicolas MH, Bodin L, J arlier V, Le Charpentier Y, Grosset J \& Viars P (1992). Nosocomial bronchopneumonia in the critically ill. Histologic and bacteriologic aspects. American Review of Respiratory Disease, 146: 1059-1066.

19. Torres A, El-Ebiary M, Padró J , González J , de la Bellacasa J P, Ramirez J , Xaubet A, Ferrer M \& Rodriguez-Roisin RL (1994). Validation of different techniques for the diagnosis of ventilator-associated pneumonia. Comparison with immediate postmortem pulmonary biopsy. American J ournal of Respiratory and Critical Care Medicine, 149: 324-331.

20. Marquette $\mathrm{CH}$, Copin MC, Wallet $\mathrm{F}$, Neviere $R$, Saulnier $F$, Mathieu $D$, Durocher A, Ramon P \& Tonnel AB (1995). Diagnostic tests for pneumonia in ventilated patients: prospective evaluation of diagnostic accuracy using histology as a diagnostic gold standard. American J oumal of Respiratory and Critical Care Medicine, 151: 1878-1888.

21. Chastre J, Fagon JY, Bornet-Lesco M Calvat S, Dombret MC, Al-Khani RA, Basset $F \&$ \& Gibert C (1995). Evaluation of bronchoscopic techniques for the diagno- 
sis of nosocomial pneumonia. American J ournal of Respiratory and Critical Care Medicine, 152: 231-240.

22. Papazian L, Thomas $P$, Garbe L, Guignon I, Thirion X, Charrel J , Bollet C, Fuentes P $\&$ Gouin F (1995). Bronchoscopic or blind sampling techniques for the diagnosis of ventilator-associated pneumonia. American J oumal of Respiratory and Critical Care Medicine, 152: 1982-1991.

23. Kirtland SH, Corley DE, Winterbauer RH, Springmeyer SC, Casey KR, Hampson NB $\&$ Dreis DF (1997). The diagnosis of ventilator-associated pneumonia. A comparison of histologic, microbiologic, and clinical criteria. Chest, 112: 445-457.

24. J ohanson J r WG, Seidenfeld J J, Gomez P, de los Santos R \& Coalson JJ (1988). Bacteriologic diagnosis of nosocomial pneumonia following prolonged mechanical ventilation. American Review of Respiratory Disease, 137: 259-264.

25. Papazian L, Autillo-Touati A, Thomas $P$, Bregeon F, Garbe L, Saux P, Seite R \& Gouin F (1997). Diagnosis of ventilatorassociated pneumonia. An evaluation of direct examination and presence of intracellular organisms. Anesthesiology, 87: 268-276.

26. Bartlett J G, O'Keefe P, Tally FP, Louie TJ $\&$ Gorbach SL (1986). Bacteriology of hospital-acquired pneumonia. Archives of Internal Medicine, 146: 868-871.

27. Torres A, Aznar R, Gatell J M, J imenez P, Gonzalez J , Ferrer A, Celis R \& Rodriguez-
Roisin R (1990). Incidence, risk, and prognosis factors of nosocomial pneumonia in mechanically ventilated patients. American Review of Respiratory Disease, 142: 523-528.

28. Horan TC, White JW, J anvis WR, Emori TG, Culver DH, Munn VP, Thornsberry C, Olson DR \& Hughes J M (1986). Nosocomial infection surveillance, 1984. Morbidity and Mortality Weekly Report, 35: 17SS29SS.

29. Schaberg DR, Culver DH \& Gaynes RP (1991). Major trends in the microbial etiology of nosocomial infection. American J ournal of Medicine, 91 (Suppl 3B): 72S$75 \mathrm{~S}$.

30. Torres A, de la Bellacasa J P, RodriguezRoisin R, de Anta MTJ \& Agusti-Vidal A (1988). Diagnostic value of telescoping plugged catheters in mechanically ventilated patients with bacterial pneumonia using the Metras catheter. American Review of Respiratory Disease, 138: 117120.

31. J imenez $P$, Torres A, Rodriguez-Roisin R, de la Bellacasa J P, Aznar R, Gatell M \& Agusti-Vidal A (1989). Incidence and etiology of pneumonia acquired during mechanical ventilation. Critical Care Medicine, 17: 882-885.

32. Pugin J, Auckenthaler R, Mili N, J anssens J P, Lew PD \& Suter PM (1991). Diagnosis of ventilator-associated pneumonia by bacteriologic analysis of bronchoscopic and nonbronchoscopic "blind" bronchoal- veolar lavage fluid. American Review of Respiratory Disease, 143: 1121-1129.

33. Chastre J, Fagon J Y, Soler P, Bornet $M$, Domart $Y$, Trouillet J L, Gibert $C \&$ Hance AJ (1988). Diagnosis of nosocomial bacterial pneumonia in intubated patients undergoing ventilation: comparison of the usefulness of bronchoalveolar lavage and the protected specimen brush and quantitative culture techniques in 147 patients. American J ournal of Medicine, 85: 499506.

34. Rello J , Quintana E, Ausina V, Castella J , Luquin M, Net A \& Prats G (1991). Incidence, etiology, and outcome of nosocomial pneumonia in mechanically ventilated patients. Chest, 100: 439-444.

35. Rodriguez de Castro F, Sole Violan J, Lafarga Capuz B, Caminero Luna J , Gonzales Rodriguez B \& Manzano Alonso J L (1991). Reliability of the bronchoscopic protected catheter brush in the diagnosis of pneumonia in mechanically ventilated patients. Critical Care Medicine, 19: 171175.

36. Espersen F \& Gabrielsen J (1981). Pneumonia due to Staphylococcus aureus during mechanical ventilation. J ournal of Infectious Diseases, 144: 19-23.

37. Inglis TJ , Sproat LJ , Hawkey PM \& Gibson JS (1993). Staphylococcal pneumonia in ventilated patients: a twelve-month review of cases in an intensive care unit. J ournal of Hospital Infection, 25: 207-210. 